\title{
CoME EASY-Synchronizing European Energy Award with Other Initiatives. Case Study: Romanian Local Communities
}

\author{
Chiara Tavella ${ }^{1}$, Charlotte Spoerndli ${ }^{2}$, Dorin Beu ${ }^{3,4, *}$ and Andrei Ceclan ${ }^{3,5}$ \\ 1 SPES CONSULTING SRL Assessment, 16124 Genoa, Italy; spesconsulting@hotmail.it \\ 2 Association European Energy Award AISBL, 1000 Bruxelles, Belgium; \\ charlotte.spoerndli@european-energy-award.org \\ 3 Faculty of Building Services Engineering, Technical University of Cluj-Napoca, 400114 Cluj-Napoca, Romania; \\ andrei.ceclan@servelect.ro \\ 4 Romania Green Building Council, 011753 Bucharest, Romania \\ 5 SERVELECT ESCO SRL, 400624 Cluj-Napoca, Romania \\ * Correspondence: dorin.beu@insta.utcluj.ro or dorin.beu@rogbc.org; Tel.: +40-7-2366-1536
}

Citation: Tavella, C.; Spoerndli, C.;

Beu, D.; Ceclan, A. CoME

EASY-Synchronizing European

Energy Award with Other Initiatives.

Case Study: Romanian Local

Communities. Energies 2021, 14, 6248.

https://doi.org/10.3390/en14196248

Academic Editor: Pedro Faria

Received: 16 August 2021

Accepted: 28 September 2021

Published: 1 October 2021

Publisher's Note: MDPI stays neutral with regard to jurisdictional claims in published maps and institutional affiliations.

Copyright: () 2021 by the authors. Licensee MDPI, Basel, Switzerland. This article is an open access article distributed under the terms and conditions of the Creative Commons Attribution (CC BY) license (https:// creativecommons.org/licenses/by/ $4.0 /)$.

\begin{abstract}
CoME EASY is a European Union H2020 project started in May 2018, which aims to help local public authorities secure a more sustainable energy and climate policy, in line with the New Green Deal and Fit for 55 initiatives. The main idea of CoME EASY is to offer an integrated package of on-line tools that synchronize European Energy Awards (EEA) with Covenant of Mayors (CoM), ISOs, Smart Cities, and other initiatives that allow local communities to have multiple commitments for energy efficiency and climate with less effort. EEA is a quality management and awarding system for municipalities and regions, which started in 1988 in Switzerland and now includes more than 1700 municipalities from 8 countries and 10 new pilot countries with more than 65 million people belonging to the local communities that are involved. There are six main areas of activity in EEA (Development and Spatial Planning Strategy, Municipal Buildings and Facilities, Supply and Disposal, Mobility, Internal Organization, Communication and Cooperation) through which municipalities are driven by advisors so as to receive a score in percentage for each area, which further allows them to compare with other communities. Romania has been an EEA pilot country since 2016 and, despite initial problems in implementing the system, now has three communities, Iași (Romania second largest city), Alba Iulia (the so-called other Romanian capital), and Vama Buzăului, included in CoME EASY. These cities tested frameworking tools and managed to be assessed with EAA tools, and developed a Sustainable Energy and Climate Action Plan synchronously. Owing to the CoME EASY tools, all of these communities were able to deliver key performance indicators that are in line with the United Nations Sustainable Development Goals.
\end{abstract}

Keywords: European Energy Award; covenant of mayors; sustainable energy and climate action plan

\section{Introduction}

The main target of the H2020 project, CoME EASY (grant agreement number 785033) [1,2], is to synchronize European Energy Award (EEA) [3] certification instruments with other EU initiatives, mainly Covenant of Mayors (CoM) [4], concerning energy and climate policies to accompany increasingly more municipalities in their 2030 performance and decarbonation process. EEA is a quality management and awarding system for municipalities and regions, which started in 1988 and now includes more than 1700 municipalities from 8 countries and 10 new pilot countries with more than 65 million people involved [3].

EEA is a bottom-up private initiative whose aim was to support municipalities for planning and implementing energy and climate measures by improving energy efficiency and increasing the use of renewable energy sources. It began in 1988 in Switzerland under the name Energiestadt or Cite de l'Energie, and currently the most-used energy and climate management tool, which is endorsed by Swiss Federal authorities. 
Afterward, it was used under the name European Energy Award in Germany, Italy, France (known as Cit'ergie), Austria (known as e5), Luxembourg (known as PacteClimat), Monaco, and Lichtenstein. Each municipality is assessed on six main areas of activity in EEA: Development and Spatial Planning Strategy, Municipal Buildings and Facilities, Supply and Disposal, Mobility, Internal Organization, and Communication and Cooperation. Results are described as a percentage of effective possibilities for a total of 79 measures.

After the assessment of all six areas, a percentage is reported for each area and an average percentage for the entire municipality. If the percentage is between 50 and $75 \%$, the community is recognized through a diploma: European Energy Award and if the percentage is above $75 \%$ it become a European Energy Award Gold. The award is valid for four years and then a new assessment is necessary.

The 79 measures are adapted for each country, depending on legislation and level of ambition. Reports are completed by EEA advisors on the EEA system, called Energy Management Tool (EMT), and it is checked by EEA auditors. At the end of an EEA assessment, a radar chart is produced (Figure 1), which presents the percentage for each area, with effective and planned measures.

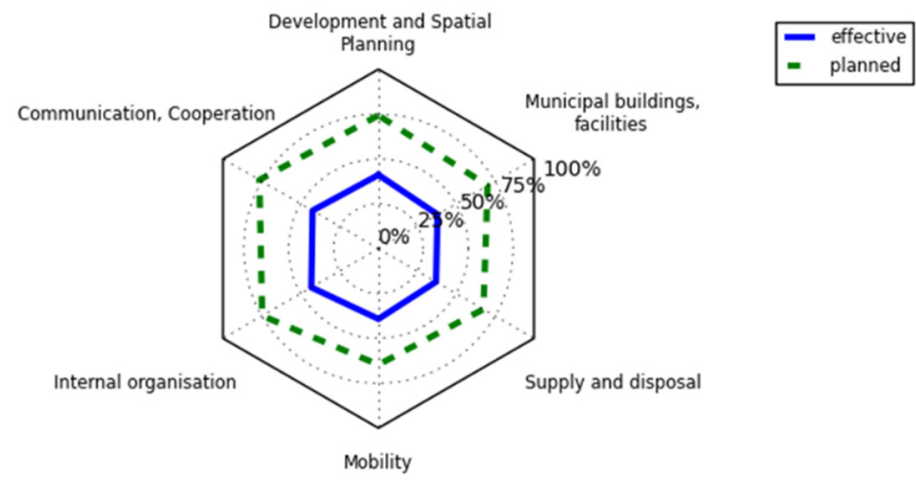

Figure 1. EEA radar chart for the city of Iași, Romania. The blue line shows effective measures and the green dotted line the planned measures.

Even though it is widely used by municipalities in eight countries, little is known about EEA compared with Covenant of Mayor (CoM), supported by the European Commission. Searching the Web of Science for papers for titles with European Energy Award showed no result, but when searching for Covenant of Mayors, 25 titles were returned. When searching about the topic, one result appeared concerning European Energy Award (in [5]) and 101 for Covenant of Mayors. On Google Academic, there are also five titles referring to the European Energy Award [6-10]. This may explain the small numbers of references in this paper, as this report is one of the first covering EEA as a management system process used by 1700 municipalities throughout Europe, which will play a crucial role in becoming decarbonized cities [11,12].

Taking into consideration several initiatives supporting local authorities in energy and climate policies, the idea of CoME EASY was to bring together EEA, CoM, ISO [13], and Smart Cities [14].

In order to reach the European Green Deal [15] for reducing emissions $55 \%$ by 2030 and becoming climate neutral by 2050, municipalities are encouraged to prepare and monitor Sustainable Energy and Climate Action Plans (SECAPs) $[16,17]$. To assist municipalities, CoME EASY creates EEA tools and procedures that are in line with CoM requirements. From now on, an EEA municipality can become a CoM signatory and prepare a SECAP by using the EEA platform's new tools by implementing only one synchronized evaluation.

Thus, the CoME EASY project does not aim to develop a new initiative, but instead manages to use synergies of existing programs and simplifies the data transfer between them. The operative target of CoME EASY (Figure 2) is to create an open "support package" for the planning and implementation activities in the fields of Sustainable Energy and 
Climate Policy, to achieve the EU 2030 targets facilitating a user-friendly, comprehensive, integrated and coproductive procedure.

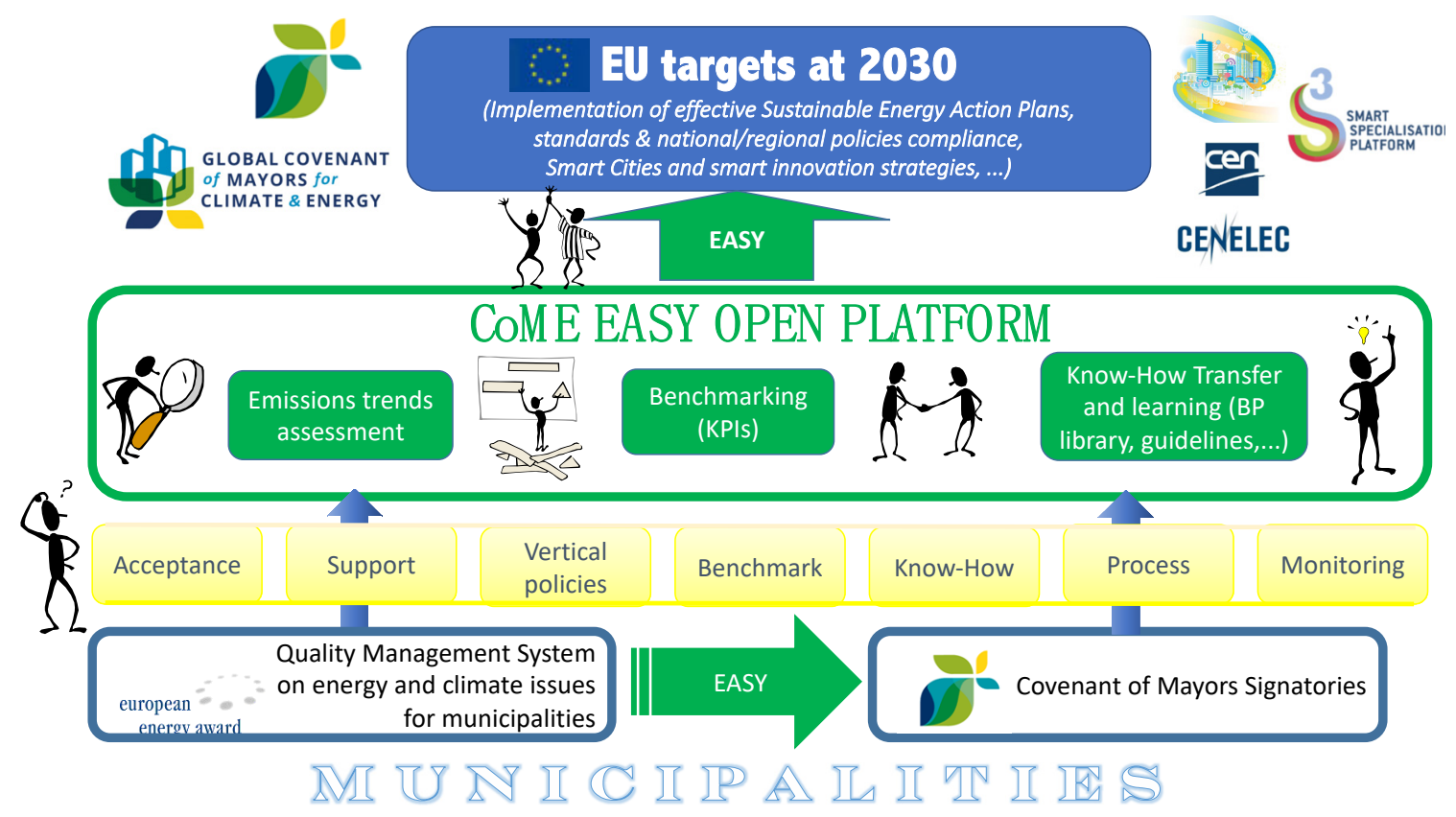

Figure 2. The CoME EASY Open Platform.

The support package will be hosted on the project's Open Platform (OP) (Figure 1) whose architecture has been defined to optimize system performances, user's experience, and data transferability from the EEA's own system EMT. A project webpage has been created and embedded in the European Energy Award website. From this project website, the user is able to access the Open Platform tools that are hosted in an open section of the EMT system, to enhance data transferability.

The CoME EASY project delivers a range of useful interacting tools and materials that can be divided into three main groups:

\subsection{Emission Path Tool-EPT}

- $\quad$ BEI/MEI calculator: The baseline emissions inventory (BEI) and monitoring emissions inventory (MEI) as a standardized data collection process provide the foundation of the EPT. The tool includes an energy accounting and greenhouse gas emissions (GHG) calculation screen mirroring SECAP balancing (BEI/MEI), interfacing with community tools (possibly allowing monthly/yearly energy consumption importation from utilities in Excel) and SECAPs.

- Scenario calculator: The scenario calculator provides the possibility for the municipality to enter diverging scenarios, which allow analyzing paths/strategies under different assumptions (e.g., population growth, deep renovation for existing buildings, district heating decarbonation, electrification of mobility).

- Energy and emission reduction path assessment tool (EERPAT): Finally, the EERPAT allows for comparing the ambition and effectiveness of one chosen reduction path (primary reduction path) to national/regional and European reduction paths. It displays historic BEI/MEI results together with future reduction paths and evaluates the ambition of planned and realized reduction paths compared with national and EU goals (e.g., COM targets).

\subsection{SECAP Creator and ISO Facilitator}

The SECAP creator is designed to enable participating cities to enter the CoM exporting/importing data in suitable formats. The ISO facilitator is aimed at supporting cities in 
the fulfilment of ISO 50001 requirements. Two downloadable calculation tools are provided to support the data definition:

- Mitigation actions calculator: a downloadable supporting tool for the three initiatives to evaluate the overall impacts of the mitigation measures (energy savings, emission reduction, and costs);

- Public buildings database: a supporting template for the data collection regarding public buildings to fulfil ISO information needs and to enrich EEA and CoM;

The data collected yearly during an EEA process in the EMT and through the CoME EASY tools (EPT, key performance indicators (KPIs), best practices, mitigation actions calculator, and public buildings database) can be structured according to CoM and ISO requirements, thus facilitating mutual exchange and multiple engagement.

\subsection{Benchmarking Tools}

- KPIs dashboard for benchmarking, compliant with the main systems in use at EU level;

- Best Practice Library: collects best practices from the cities involved and from interested networks. The database is user friendly with the possibility to sort the actions by municipality, theme, or EEA catalogue reference. The best practices belong to all the issues of municipal interest and illustrated in a user-friendly standard template to be published on the web (following the examples in CoM).

The project carried out a pilot test developing SECAPs (including emission inventories, KPIs, and best practices) with ambassador municipalities and experienced energy advisors to collect their contributions and feedback. Based on these experiences, the package will be finalized and the developed open support package further implemented and disseminated to all interested municipalities in all participating countries, creating the way for large use of these facilitating tools and procedures; at least 95 municipalities will be supported with six million inhabitants, while the capacity building action will involve 150 energy advisors, 300 municipal staff, and more than 500 stakeholders.

The project began in May 2018 and ended in September 2021, and was implemented by an international consortium consisting of partners from seven European countries. The effects will continue after the project end, owing to the promotion and dissemination activity; some results have already been provided for the impacts by 2030, based on the partners (EEA network) active involvement.

\section{CoME EASY Key Performance Indicators-KPIs}

Being compliant with the main initiatives in the field of sustainable energy and climate change mitigation, the project is aligned with all the recognized approaches (such as EEA, ISO, CoM, SCIS, etc.), and its KPIs database can be exportable and reused as a gateway to enter multiple commitments and benchmarking.

The set of project KPIs was defined at the beginning of the project, together with the related open tool requirements (services/functionalities and interactions with the other tools under development) for the inclusion in the CoME EASY open platform. The CoME EASY open platform already provides several further supporting tools for calculation together with a visualization dashboard for benchmarking.

With technical support from their EEA advisors, the ambassador municipalities involved in the project were asked to test the tools to give feedback concerning the availability of the inputs, the usefulness of the outputs, and the user friendliness of the calculations. Analyzing the feedback received, especially from the local urban energy managers, the project provided the final set of KPIs, the upload interface for calculation and the visualization dashboard, and the tool guide for training sessions.

The main goals achieved in the set selections were:

- Agreeing on a list of indicators that are valuable and reliable for the municipalities to evaluate their progress over time;

- Determining which existing measurement indicators simplify data collection and use; 
- Convincing stakeholders on the indicators proposed (availability throughout Europe).

\subsection{Methodology}

The methodology followed for monitoring and evaluation of the municipalities' energy and sustainability performance and for the measurement of the impact that the implementation of specific interventions has in the city is based on two different levels:

(1) Municipal level: refers to the overall performance of the city, which is evaluated through a set of multidimensional KPIs, including several different fields (energy and climate, but also economy, social, and governance). This set integrates most of the information requested by the initiatives that the project aligns with [18-21]. The list of KPIs could be differentiated into a core set of mandatory values and an additional set of voluntary measures [22-27].

(2) Project level: especially when evaluating the impacts of best practices, a more specific monitoring at intervention level is useful for detailed evaluation of different actions. The KPIs related to best practices are related to the cost of measures undertaken and the impacts in terms of energy savings, $\mathrm{CO}_{2}$ reduction, and local generation of renewable energy sources (RES).

Regarding the municipal level, a first list of indicators was developed by adapting and integrating the existing methodologies, so that it could be exported easily to other cities. Besides energy, which is the main interest of the project, many other issues have been included, linked with climate protection, sustainability, and quality of life, by following a holistic and integrated approach. The structure of the set, as shown in following section, is inherited from the EEA management tool to be consistent with the project approach.

\subsection{Ambassador Cities}

For each participating nation, several ambassador cities have been involved since the beginning, in order to test the project tools and receive feedback for their optimization (Figure 3).

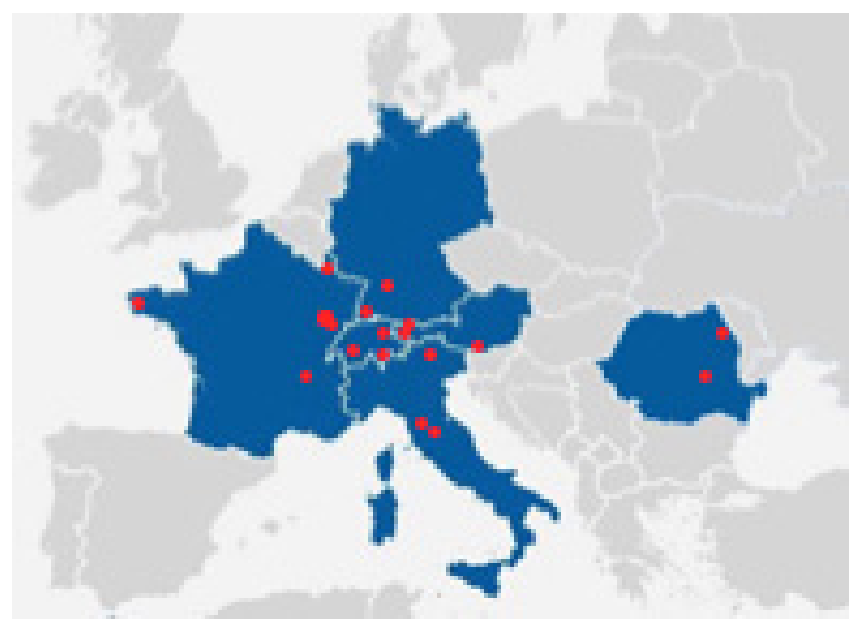

Figure 3. Map of the participant countries.

These municipalities were selected because of their experience concerning commitment in sustainable targets and in different initiatives; most are in the European Energy Award program and demonstrated excellent results (many Gold Awarded cities), several are CoM/Mayors Adapt signatories, while there are also two ISO certificated municipalities (ISO 9001, 14001, and 50001) and two Smart Cities.

The size range varies, from a city of about 400,000 inhabitants to small towns, and their geographic boundary conditions. All ambassador municipalities are supported by qualified EEA advisors. 


\subsection{Test Feedback}

The test was developed on a first list of KPIs provided in Excel format together with the explanations available. Municipalities had five months to work through their KPIs database and it was their decision for which years to provide data.

The results were influenced by data accuracy, quality, and replicability of the measure. All indicators had to be designed according to a bottom-up approach, which is much more reliable than top-down statistics but more difficult to follow because of capillary data collection.

The analysis pointed out several critical points in the use of key performance indicators and positive feedback:

Data sources: new KPIs or new units for calculation required much time to be proceeded by municipalities; this is likely the reason the next monitoring will be smoother and faster.

The interaction with the other tools under test phase is still not clear and it sometimes causes double work; with guidance and training foreseen in the next project phase, this problem will be solved.

Comparability and benchmarking: there are differences between municipalities regarding size, geographical position, and the period of the assessment, which make the comparison between cities difficult and less reliable, but generally, the normalization of units has worked.

All KPIs are gathered by third-party advisors, who are independent and qualified personnel; this is important for acceptance.

There is always discussion concerning the usefulness of the indexes. At the end, what the project needs is a valuable set which is as small as possible and not confusing to stakeholders. Some KPIs were changed into optional and others confirmed only at the end of the test phase, but it is advisors' work to convince municipalities about the interest in some indicators. This will be part of the training-municipalities cannot be unaware of all other initiatives and their benefits, and occasionally they are overwhelmed by the efforts needed for the data provision.

The results from the ambassadors test demonstrate that general data are available (in use for several purposes); mandatory indicators have been mostly worked out for at least one year, while optional indicators are more difficult, even if the KPI is occasionally evaluated as useful for policy making. In most the cases, the KPIs database covers $3-5$ years of monitoring.

\subsection{Priority}

The indicators have been differentiated since the beginning into mandatory and optional fields. The prioritization of the set allows municipalities a step-by-step approach, collecting data and providing calculations in different phases, considering the workload but also the continuous improvement target in detailing the monitoring/control system. There are also supporting general data, for example, population and climatic zone.

The three categories follow:

1. General Data, including the information needed for the calculation or "normalization" of the other KPIs. These data are useful in the benchmarking procedure to compare different situations and to frame the context.

2. Mandatory fields with the most relevant indexes for the evaluation of the energy and climate performance of the municipality.

3. Optional KPIs for collection of other pertinent data for detailing different fields of influence.

In the discussion following the selection phase, some KPIs have already been moved from one category to another; further needs have been collected and analyzed in the test. 


\section{Case Study: Romanian Local Communities}

From 2014 on, by Romanian energy efficiency law and in all the local communities with more than 20,000 inhabitants, the public authorities have been obliged to employ an urban energy manager, authorized by the Ministry of Energy. This is a key issue in the effective implementation of the policy and decision maker commitments. The EEA initiative and pilot cases in Romania fully involved these urban energy managers.

Since 2016, Romania has been an EEA pilot country, with Romania Green Building Council (RoGBC) in charge with EEA license. From 2016 to 2018, the EEA methodology was adapted to Romania, owing to support from the Swiss State Secretariat for Economic Affairs SECO, through ENCO company. EEA implementation in Romania had a difficult start due to Romanian bureaucracy and lack of interest at the beginning from local authorities. Since the involvement of RoGBC and SERVELECT ESCO (as subcontractor) in H2020 CoME EASY, the interest in EEA and especially in the new EMT tool has risen and there is an improved municipal perception; approximately 35 urban energy managers are now engaged in the Romanian Society of Energy Managers and Auditors Association.

There are two local communities, called "Ambassador Cities"-Iasi and Vama Buzăului-which are included in CoME EASY to test and develop the tools. Iasi is the second largest city in Romania, with a population of more than 378,871 and highly interested in improving their energy and climate action plan. Vama Buzăului, a village of 3554 people, located in central Romania and the Carpathian Mountains, is interested in sustainable development of the rural area. These two communities were assessed on the EEA frame, developing in parallel the process, owing to the tools provided by the Sustainable Energy and Climate Action Plan (SECAP) and supporting documents for the ISO 50001 implementation. Since 2010, Iași municipality was trying to finalize the BEI; in 2020, as a result of CoME EASY support, both BEI and SECAP were finished. The resulting KPIs for these two Romanian communities are presented in Table 1.

Table 1. Key performance indicators, connection to UN goals, and values for Iași and Vama Buzăului.

\begin{tabular}{|c|c|c|c|c|}
\hline Indicator & UN Goal & UN KPI & Iași & Vama Buzăului \\
\hline Size $\left[\mathrm{km}^{2}\right]$ & & & 93.91 & 156.63 \\
\hline Land use $[\%]$ & 11 & 11.3 .1 & 35.60 & 2.40 \\
\hline Climate resilience strategy and risk reduction analysis & $1,11,13$ & 1.5.4, 11.b.2, 13.1 .3 & No & No \\
\hline Existence of local sustainability/climate plan, CoM & 12,13 & $12.7 .1,(12.1 .1), 13.2 .1$ & Yes & No \\
\hline Existence of Smart Cities strategies & & & Yes & No \\
\hline Frequency of monitoring and indicator calculation [months] & 17.18 & & 12 & $\mathrm{~N} / \mathrm{A}$ \\
\hline Participation: voters to last municipal elections [\%] & 16 & $((16.7 .2))$ & 33.56 & 61.33 \\
\hline Social housing stock [\%] & & & 3.3 & 0 \\
\hline Public buildings consumption [MWh/cap/yr] & & & 0.28 & 0.288 \\
\hline Vehicles consumption [MWh/cap/yr] & & & 1.76 & 1.04 \\
\hline Public street lighting consumption [MWh/cap/yr] & & & 0.03 & 0.087 \\
\hline Electricity by RES [\%] & 7 & & 40 & 27 \\
\hline Heating by RES [\%] & 7 & & 0 & 95 \\
\hline Municipal solid waste per capita [t/cap/yr] & 11 & $((11.6 .1))$ & 0.41 & 0.51 \\
\hline Recycling rate [\%] & 11,12 & 12.5.1, ((11.6.1)) & 25.65 & 40.67 \\
\hline Litres of water used per capita [L/cap/yr] & 6 & $(6.4 .1)$ & 42180 & 16425 \\
\hline Water losses [\%] & 6 & $(6.4 .1)$ & 42.12 & 16.23 \\
\hline Access to public free WiFi [number of $\mathrm{m}^{2} /$ cap] & $17.6,17.8$ & $((17.6 .2)),((17.8 .1))$ & 4.51 & 0 \\
\hline Climate Koppen-Geiger classification & & & $\mathrm{Dfb}$ & Et \\
\hline $\mathrm{CO}_{2}$ emissions $\left[\mathrm{tCO}_{2} / \mathrm{cap} / \mathrm{yr}\right]$ & & & 1.91 & 0.95 \\
\hline Nitrogen dioxide emissions $\left(\mathrm{NO}_{2}\right)\left[\mu \mathrm{g} / \mathrm{m}^{3}\right]$ & & & 31.02 & $\mathrm{~N} / \mathrm{A}$ \\
\hline $\mathrm{PM}_{10}$ concentration $\left[\mu \mathrm{g} / \mathrm{m}^{3}\right]$ & 11 & $(11.6 .2)$ & 41.02 & $\mathrm{~N} / \mathrm{A}$ \\
\hline Annual final energy consumption [MWh/cap/yr] & 7 & (7.3.1 energy intensity) & 6.74 & 3.12 \\
\hline Renewable electricity generated within the city [\%] & 7 & & $<0.2$ & $<0.5$ \\
\hline
\end{tabular}


Table 1. Cont.

\begin{tabular}{|c|c|c|c|c|}
\hline Indicator & UN Goal & UN KPI & Iași & Vama Buzăului \\
\hline Renewable heat generated within the city [\%] & 7 & & 0 & 95.53 \\
\hline Smart energy meters [\% of buildings] & & & 18.21 & 0 \\
\hline Access to public transport [inh] & 9,11 & 11.2.1 (9.1.2) & 82.32 & 0 \\
\hline Number of annual PT trips per capita & & & 211.12 & 0 \\
\hline Number of fossil fuelled vehicles per capita & & & 0.31 & 0.26 \\
\hline Length of bike route network $[\mathrm{km} / 100,000 \mathrm{inh}]$ & & & 12.17 & 0 \\
\hline Number of electric charging stations for EV [n/100,000] & 9 & & 11.91 & 0 \\
\hline $\mathrm{km}^{2}$ restricted areas & & & 0.82 & 0 \\
\hline Access to vehicle sharing solutions & 9 & & 0 & 0 \\
\hline Population & & & 378,871 & 3554 \\
\hline Density [inh $\left./ \mathrm{km}^{2}\right]$ & & & 4034.40 & 22.69 \\
\hline Population increase rate [\%] compared to 2011 & & & 30.46 & 10,31 \\
\hline Tourism intensity [nights $/ 100,000]$ & 8 & (8.9.1 related to GDP) & 5.25 & 0.37 \\
\hline City's unemployment rate [\%] & 8 & 8.5 .2 & 3.16 & 0.92 \\
\hline Fuel poverty [\% of households] & 1 & (1.4.1 basic services) & 3.48 & 1.95 \\
\hline
\end{tabular}

The implementation team performed site visits and interviews with the two administrations, both with technical staff and with the mayors, to understand their vision and strategies.

Iași has an appointed urban energy manager who handles the day-by-day energyrelated issues, follows the progress on the proposal, and reports to Ministry of Energy of the Energy Efficiency annual programme. In October 2020, Vama Buzăului was the first community certified according to EEA methodology, scoring 38.5\%, followed by Iași in April 2021 with a score of $40.6 \%$.

As a follow-up, the approach and related tools from CoME EASY project have been proposed to several other local communities in Romania. SERVELECT has ongoing urban energy management contracts with these communities. As a result, the so-called other capital of Romania, Alba Iulia municipality, joined and received EEA certification together with the SECAP synchronous preparation.

\section{Link with Other Initiatives: UN SDGs}

In the CoME EAsy project, based on the EEA network experience, there have been other achievements to be capitalized upon and considered. It started with energy, which was the main interest for EEA at the beginning and continued with a holistic and integrated approach that includes many other issues, such as sustainability and smart city vision. The structure of the KPIs is based on the EMT model, so as to be consistent with the project approach. The approach is in line with the ISO philosophy $(14001,50001,37120)$; monitoring cities progress in a continuous improvement process. During the test phase, the link and compliance of the set was checked with the UN Sustainable Development Goals and the related indicators system.

The United Nations defines 17 Sustainable Development Goals (SDGs) as a call for action by 2030. Standards such as EEA and ISO enable efforts to be harmonized to achieve the SDGs, which appear to be the key to fulfilling and monitoring the goals, thereby helping public authorities and stakeholders make the SDGs a reality.

Analyzing the resolution adopted by the General Assembly on 6 July 2017 and the 2030 Agenda for Sustainable Development, a comparison was carried out: the CoME EASY KPIs results correspond to several specific indicators in different areas, as shown in Table 1.

\section{Conclusions, Contributions, and Further Work}

This paper presents outstanding results of the first test phase for the definition and calculation of the standard set of KPIs related to European Energy Award (EEA), as a 
synchronizing and enhanced tool to deliver SECAPs and ISO 50001 evaluation for local communities. The work, carried out through the involvement of 18 ambassador cities, including three from Romania, has demonstrated to be very useful in describing the energy and climate state of municipalities, and allows for benchmarking, despite the different size of the municipalities and their geographical position; generally, the normalization of the units has worked.

The response from the evaluated municipalities has been relevant and demonstrated that general data are available. The KPIs defined as "mandatory" have generally been established for at least one year ( $84 \%$ of mandatory KPIs were collected from the ambassadors), while optional indicators are more difficult, even if the KPI sometimes is evaluated as useful for policy making. In most cases, the KPIs database covers from 3 to 5 years of monitoring.

The positive feedback demonstrated the general interest of municipalities in benchmarking, their need of data for communication and stakeholder engagement, and the support and quality check provided by advisors. Many resulting data are already available, to be redefined only in terms of normalization or measurement unit. Aspects that were improved in the next project steps were the links of several inputs with other tools (to be highlighted or automated) and the description of the calculation methodology, which was already revised following feedback, and will be more detailed in the training materials.

The standardization of the set and multiple validity of the KPIs were appreciated, even with a risk related to possible updating of KPIs in different initiatives. Other risks were detected in the comparability of the values, even if the normalization applied was evaluated positively.

Even if some indicators were proven to be not user-friendly, it was decided to maintain these as optional, because of their usefulness in understanding some dynamics of urban development, consumption trends, mobility behaviors, and effectiveness of the implemented policies and actions.

In this case, it will be the work of the advisors to convince municipalities concerning the interest in some indicators, which will be part of the scheduled trainings. In other cases, the level of feedback was limited due to the difficulty for the municipality/advisor to obtain the information from the facility/system managers. This has been a major barrier for small-scale municipalities that have limited control over some aspects such as water systems management, waste disposal, or public transport, which belong to the public utilities companies.

The involvement of Romanian municipalities has shown that, despite economic and geographical differences with the other cities involved, similar KPIs were obtained. Owing to their participation in the CoME EASY project, local authorities gained access to two assessment systems (EEA and CoM), collected extensive energy and climate data, and managed to calibrate their energy and climate policies. Furthermore, regardless of the commitment approach selected by the local public authorities-SECAP, EEA, or ISO 50001the presence of professionals such as urban energy managers is essential, both in data collection and for energy and climate projects initiation and follow-up measurement and verification of results.

Author Contributions: Conceptualization, C.T. and C.S.; methodology, C.T.; data curation, A.C.; writing-original draft preparation, D.B.; writing-review and editing, D.B.; visualization, C.T.; supervision, D.B.; project administration, C.T.; funding acquisition, D.B. All authors have read and agreed to the published version of the manuscript.

Funding: This research was funded by CINEA H2020, grant number 785033-CoME EASY.

Data Availability Statement: Data for Table 1 were supplied by SERVELECT SRL.

Acknowledgments: Authors wish to thank to all members of the CoME EASY for their important contribution to this paper. 
Conflicts of Interest: The authors declare no conflict of interest. The funders had no role in the design of the study; in the collection, analyses, or interpretation of data; in the writing of the manuscript, or in the decision to publish the results.

\section{References}

1. Come Easy. Available online: https://www.european-energy-award.org/eu-project-come-easy (accessed on 16 August 2021).

2. Tavella, C.; Pessina, A. Report on KPIs for Ambassador Cities, H2020 CoME Easy report. 2019.

3. European Energy Award. Available online: https://www.european-energy-award.org (accessed on 16 August 2021).

4. Covenant of Mayors Initiative. Available online: https:/ / eumayors.eu (accessed on 16 August 2021).

5. Strassl, I. Community strategies for energy efficiency successful examples from Austria. Open House Int. $2010,35,25-32$. [CrossRef]

6. Dinges, K. European Energy award-das qualitaetsmanagement fuer europaeische kommunen. ET Energiewirtschaftliche Tagesfragen 2002, 52, 616 .

7. Stenitzer, M.; Grim, M. The "European energy award" for sustainable communities. In ECEEE 2005 Sumer Study; European Council for an Energy-Efficient Economy: Stockholm, Sweden, 2005.

8. Strasser, H. e5-Program for energy efficient communities, presentation for the European conference. In A Future with Zero $\mathrm{CO}_{2}$ Emissions; European Council for an Energy-Efficient Economy: Stockholm, Sweden, 2006.

9. Mader, S.; Leindl, A. Act Local-in a European wide network-e5 and the European energy award-a way to realise permanent and sustainable energy-efficiency projects in communities. In ECEEE 2007 Sumer Study; European Council for an Energy-efficient Economy: Stockholm, Sweden, 2007.

10. Machoczek, T. European energy award: Hilfestellung fuer preiswuerdige effizienz. Beratende Ingenieure 2007, 37, 33-35.

11. Rauland, V.; Newman, P. Decarbonising Cities_Mainstreaming Low Carbon Urban Development; Springer: Berlin/Heidelberg, Germany, 2015; ISBN 978-3-319-15506-7.

12. Quinio, V.; Rodrigues, G. Net Zero: Decarbonising the City. Available online: www.centreforcities.org (accessed on 8 September 2021).

13. Smart Cities Information System. Available online: https://smartcities-infosystem.eu (accessed on 16 August 2021).

14. ISO 50001 and Data for Cities Portal. Available online: http://www.dataforcities.org (accessed on 16 August 2021).

15. Delivering the European Green Deal. Available online: https://ec.europa.eu/info/strategy/priorities-2019-2024/europeangreen-deal/delivering-european-green-deal_en (accessed on 1 September 2021).

16. Kona, A.; Bertoldi, P.; Kilkis, S. Covenant of mayors: Local energy generation, methodology, policies and good practice examples. Energies 2019, 12, 985. [CrossRef]

17. Kona, A.; Monforti-Ferrario, F.; Bertoldi, P.; Baldi, M.G.; Kakoulaki, G.; Vetters, N.; Thiel, C.; Melica, G.; Vullo, E.L.; Sgobbi, A.; et al. Global covenant of mayors, a dataset of greenhouse gas emissions for 6200 cities in Europe and the Southern Mediterranean countries. Earth Syst. Sci. Data 2021, 13, 3551-3564. [CrossRef]

18. The Reference Framework for Sustainable Cities Initiative. Available online: http:/ /rfsc.eu (accessed on 16 August 2021).

19. H2020 CityKeys Project. Available online: http:/ / www.citykeys-project.eu (accessed on 16 August 2021).

20. Regeneration Model for Accelerating the Smart Urban Transformation. Available online: http://www.remourban.eu/ (accessed on 7 April 2020).

21. FP7 STEEP and Its Follow up H2020 SCC1 Replicate Project. Available online: https://replicate-project.eu (accessed on 16 August 2021).

22. Capehart, B.L.; Turner, W.C.; Kennedy, W.J. Guide to Energy Management, 8th ed.; Capehart, B.L., Turner, W.C., Kennedy, W.J., Eds.; The Fairmont Press: Lilburn, GA, USA, 2016.

23. Roosa, S.A.; Doty, S.; Turner, W.C. Energy management handbook. In Energy Management Handbook; Informa UK Limited: London, UK, 2020.

24. Kazuhiko, Y. Total Energy Management Handbook; Kazuhiko, Y., Ed.; Energy Conservation Center Japan: Tokyo, Japan, 2005.

25. Moss, K. Energy Management in Buildings; Taylor and Francis: Milton, UK, 2006.

26. Levermore, G. Building Energy Management Systems; Taylor and Francis: Milton, UK, 2000.

27. Nikolaou, T.; Kolokotsa, D.; Stavrakakis, G.; Apostolou, A.; Munteanu, C. Managing Indoor Environments and Energy in Buildings with Integrated; Springer: Berlin/Heidelberg, Germany, 2015. 